\title{
Pecuária Leiteira do Rio Grande do Sul: uma análise espacial da produtividade a partir da década de 1980
}

\author{
Mariza de Almeida ${ }^{1}$ \\ Clailton Ataides de Freitas ${ }^{2}$ \\ Gabriel Nunes de Oliveira ${ }^{3}$ \\ Nilson Luiz Costa ${ }^{4}$
}

Aceite: $29 / 10 / 2021$

\begin{abstract}
Resumo
A presente pesquisa objetivou analisar o padrão de comportamento da produtividade de leite bovino no estado do Rio Grande do Sul a partir da década de 1980. Para tanto, foi realizada uma análise de cluster e da distribuição espacial da produtividade de leite bovino para as décadas de 1980, 1990, 2000, 2010 e 2019, por meio da análise exploratória de dados espaciais (AEDE). Os resultados apontaram, primeiro, modificações na distribuição espacial da produtividade de leite bovino no estado do Rio Grande do Sul, principalmente, com o deslocamento da região Metropolitana de Porto Alegre (1980) para a região Noroeste e Nordeste Rio-Grandense (2019); em segundo lugar, a formação de clusters na região Noroeste Rio-Grandense, com destaque do tipo alto-alto, indicando que municípios com produtividade alta estão circundados de municípios com alta produtividade e, na região Sudoeste apresentase um cluster do tipo baixo-baixo, ou seja, municípios com produtividade baixa estão rodeados por municípios vizinhos com baixa produtividade.
\end{abstract}

Palavras-chave: Produtividade de leite. Distribuição espacial. Rio Grande do Sul.

\section{Dayri farming in Rio Grande do Sul: a spatial analysis of productivity from the 1980s}

\begin{abstract}
The present study aimed to analyze the pattern of bovine milk yield behavior in the state of Rio Grande do Sul from the 1980s onwards. A cluster analysis and spatial distribution of bovine milk yield was performed for the 1980s, 1990, 2000, 2010 and 2019, through exploratory spatial data analysis (ESDA). The results pointed out, firstly, changes in the spatial distribution of bovine milk yield in the state of Rio Grande do Sul, mainly with the displacement of the Metropolitan of Porto Alegre region (1980) to the Northwest and Northeast Rio-Grandense region (2019); secondly, the formation of clusters in the northwest Rio-Grandense region, highlighting the high-high type, indicating that municipalities with high productivity are surrounded by municipalities with high productivity, and in the Southwest region there is a cluster of low-municipalities with low productivity are surrounded by neighboring municipalities with low productivity.
\end{abstract}

Key words: Milk productivity. Spatial Distribution. Rio Grande do Sul.

\footnotetext{
${ }^{1}$ Doutoranda do Programa de Pós-Graduação em Economia Aplicada (ESALQ/USP).

Email:mariza.de.almeida@hotmail.com.

${ }^{2}$ Doutorado em Economia Aplicada pela ESALQ/USP. Professor do Programa de Pós-Graduação em Economia e Desenvolvimento - UFSM. Email:Icv589@gmail@gmail.com.
}

${ }^{3}$ Doutorado em Extensão Rural. Professor na Universidade Federal de Santa Maria - UFSM.

Email: ambientalgnu@uol.com.br.

${ }^{4}$ Doutorado em Ciências Agrárias. Professor na Universidade Federal de Santa Maria - UFSM.

Email:nilson.costa@ufsm.br 


\section{Introdução}

A bovinocultura leiteira, devido aos fatores climáticos, ambientais e tecnológico específicos, está inserida em todas as regiões do Brasil com características peculiáres e presente na maioria dos estabelecimentos agrícolas do País. Constituindo-se em uma das principais fontes geradoras de renda com fluxo mensal aos produtores rurais, principalmente, nos pequenos municípios com pouco dinamismo econômico, tornando-se uma das atividades com grande relevância econômica e social.

A produção de leite no Brasil representou, aproximadamente, 7,8\% do Valor Bruto da Produção Agropecuária (VBP) em 2019 (CNA, 2021) e, segundo o CEPEA (2021), o conjunto cadeia produtiva do leite (insumos, indústria e serviços), em 2017, representou 12,8\% do PIB do agronegócio no Brasil, ou $\mathrm{R} \$$ 69,4 bilhões. A pecuária leiteira brasileira estava presente em 1,176 milhões de estabelecimentos agropecuários em 2017, os quais se concentram principalmente nos estados de Minas Gerais, Rio Grande do Sul, Bahia, Paraná e Ceará (IBGE, 2021b). Esses números retratam a importância do setor lácteo, não só para o agronegócio, mas para a economia brasileira como um todo.

Com a abertura comercial e a globalização, essa cadeia sofreu profundas transformações (fim do tabelamento dos preços, menor intervenção do Estado, tecnificação da produção e maior competitividade) que auxiliaram na superação de problemas de natureza estrutural e tecnológica, deixando-a mais dinâmica e produtiva. No ano de 1974, a produção de leite de vaca no Brasil foi de 7,1 bilhões de litros e um rebanho de 10,8 milhões cabeças, já em 2019, o Brasil produziu 34,8 bilhões de litros de leite, obtidos com um rebanho de 16,2 milhões de vacas ordenhadas, o que implicou em uma produtividade de 2.142 litros/vaca/ano (IBGE, 2021a). Esses dados representam um crescimento de 391\% da produção de leite do ano de 1974 para 2019. Sendo que em 2019, Minas Gerais (9.447.532 mil litros), Paraná (4.339.190 mil litros) e Rio Grande do Sul (4.270.797mil litros) foram os estados brasileiros que apresentaram maior volume de produção.

O Rio Grande do Sul apresentou em 2019 a segunda maior produtividade de leite bovino do País, com 3.610 litros/vaca/ano (1,1 milhão vacas ordenhadas), e, há registro de produção de leite em 497 municípios que compõem o estado (IBGE, 2021a). Um fato relevante a se destacar é que Mesorregião Noroeste Rio-grandense foi, em 2019, a região com maior produção de leite bovino do País. Quanto a estrutura fundiária, de acordo com o Censo Agropecuário 2017, o Rio Grande do Sul conta com 129.877 estabelecimentos agropecuários do tipo agricultura familiar 
(116.141) e não familiar (13.736) que produzem leite, representando $35 \%$ do total do estado (IBGE, 2021b). Além disso, devido a proximidade do estado do RS com os países parceiros do Mercosul, há uma significativa concorrência no complexo lácteo.

A produção de leite passou por muitas transformações no decorrer dos últimos anos, fazendo-se necessário explorar de que forma elas foram acontecendo e impactando na distribuição espacial da produtividade leiteira do Rio Grande do Sul. Para tanto, fez-se um retrato para cada década (1980, 1990, 2000, 2010 e 2019) com o intuito de diagnosticar a evolução do padrão de correlação espacial da produtividade de leite bovino nos municípios gaúchos. Pois, conforme Vilela et al. (2017), a pecuária leiteira apresentou sinais de modernização a partir de 1950, mas o grande salto na produção se deu na década de 1980, quando passou de 7,9 milhões de toneladas em 1975 para 12 milhões de toneladas em 1985. Já no ano de 1990, ocorreram várias mudanças, como abertura comercial, fim do tabelamento de preços e aumento da demanda, as quais resultaram em aumento da produtividade no início da década de 2000 . A partir de 2000, várias políticas públicas foram sendo criadas para ajudar os agricultores, além da entrada de multinacionais, maior mecanização da produção e aumento do consumo de leite.

Cabe ressaltar, que a pecuária leiteira é uma atividade muito importante para o Rio Grande do Sul, pois, em 2019 foi classificado como terceiro maior produtor de leite de vaca e o segundo com maior produtividade no Brasil $^{5}$. Perante o ambiente de transformações da estrutura produtiva, aumento da competitividade, diferentes tipos de produtores (especializados e não especializados) e aumento da produção de leite de forma desigual, estudos sobre a distribuição espacial da produção de leite bovino no Brasil e, especificamente, no estado do Rio Grande do Sul, fazem-se necessários. Uma das formas de análisar a produção de leite bovino geograficamente, é por meio de métodos de estatística espacial, os quais analisam a autocorrelação espacial da atividade leiteira entre os municípios (se os municípios e seus vizinhos apresentam produção similares). Pode-se destacar algumas pesquisas que utilizam análise exploratória de dados espaciais para ilustrar como a produção de leite encontra-se, geograficamente distribuida, tais como: Schumacher (2013), Lemos et al. (2003), Ponciano e Scalon (2010), Marion Filho e Oliveira (2011), Silva, Camara e Telles (2016), Perobelli, Araújo Junior e Castro (2018), Capucho e Parré (2012) e Fernandes, Bressan e Verneque (2004).

Desta forma, tem-se por objetivo na presente pesquisa analisar o padrão de comportamento espacial da produtividade de leite de vaca no estado do Rio Grande do Sul, a

\footnotetext{
${ }^{5} \mathrm{Na}$ seção 2 são apresentados outros números que melhor ressaltam a grande relevância dessa atividade para a economia gaúcha.
} 
partir da década de 1980. Visto que, a produtividade de leite do Rio Grande do Sul é a maior em relação aos demais estados do País e está distribuída de forma heterogênea pelo estado, se realizará uma análise de cluster sobre a produtividade de leite na década de 1980, 1990, 2000, 2010 e 2019, por meio do ferramental Análise Exploratória de Dados Espaciais (AEDE).

Diante dessas considerações, a presente pesquisa encontra-se estruturada em cinco seções: a primeiro, é composta por esta introdução; a segunda seção aborda o comportamento da pecuária leiteira do Rio Grande do Sul a partir da década de 1980; na terceira seção apresentase a metodologia adotada, descando-se a Análise Exploratória de Dados Espaciais (AEDE), as variáveis utilizadas e a fonte dos dados. Posteriormente, na quarta seção têm-se os resultados e discussões. Por fim, tem-se as principais conlusões da pesquisa.

\section{Trajetória histórica da produção de leite bovino a partir da década de 1980}

A atividade leiteira no Brasil passou por muitas transformações de cunho estrutural e social no período compreendido entre 1980 até 2019. A busca constante dos produtores e da indústria pelo aumento da produtividade, associada aos interesses dos policy makers em que o País alcançasse a autossuficiência do consumo fez com que a cadeia produtiva do leite se tornasse atrativa ao investimento. Essa nova perspectiva incluiu a implementação de políticas públicas que proporcionaram especialização, ganhos de qualidade e produtividade para esse setor.

Em meados da década de noventa, o Brasil iniciou sua participação no Mercosul ${ }^{6}$, o qual propiciou zona livre de comércio com países da América do Sul, entre eles Uruguai e Argentina, os quais fazem fronteira com o estado do Rio Grande do Sul (RS). Devido à esta proximidade geográfica o Rio Grande do Sul sofreu grande impacto no complexo leiteiro. Além disso, tem-se, nessa mesma época, a desregulamentação do mercado lácteo com o fim do tabelamento, a abertura comercial para além do Mercosul e a estabilização da economia (implantação do Plano Real). Essas consorciações de fatos fizeram com que o Brasil se envolvesse em um ambiente competitivo, com uma série de desafios, entre eles a busca pelo aumento da produção a baixos custos (CASTRO et al., 1998; JANK; GALAN, 1998).

Para Castro et al. (1998), esse novo ambiente econômico fez com que a cadeia leiteira passasse por adequação na sua estrutura, se espelhando nos países que detinham grande

\footnotetext{
${ }^{6}$ O Mercosul é um bloco econômico criado em 1991, através do Tratado de Assunção, que tem por objetivo promover
} a integração dos países por meio da livre circulação de bens, serviços e fatores produtivos (BRASIL, 2021). 
produção do mundo. Ou seja, foi necessário que o Brasil implementasse tecnologia em todos os elos da cadeia (produção, industrialização e distribuição), para assim estar mais próximo de seus concorrentes. Nesse momento, as empresas nacionais recuaram, pois necessitavam de grande modernização e profissionalização, dando espaço para expandir no país as indústrias multinacionais, as quais tinham grande potencial, conseguiam atender todo o mercado interno e buscavam exportar (MARION FILHO; OLIVEIRA, 2011; VILELA et al., 2017).

Grande foi o esforço realizado para que a produção de leite de vaca se tornasse tecnificada, porém, o País estava saindo de um ambiente onde a produção era consumida internamente e sem nenhuma concorrência externa, sendo necessário organizar a produção em todos os âmbitos, da nutrição do rebanho, a reprodução, ao melhoramento genético, ao manejo até a sanidade. Ademais, para a reestruturação acontecer, o produtor precisava organizar-se (através da compra de insumos e medicamentos de qualidade), o Governo deveria implementar programas de melhoramento do rebanho, sistemas de compra do leite, crédito que estivesse em conformidade com as necessidades do produtor (instalações, tratamento do solo (pastagens), armazenagem e compra de insumos e máquinas (tanques de resfriamento)) e criação de associações/cooperativas (CASTRO et al., 1998; FERNANDES, 1995; PEDROSO, 2001).

Diante desse novo cenário, as perspectivas dos estudiosos da área leiteira (tecnólogos, economistas e zootecnistas), era que o número de produtores iria diminuir, permanecendo somente aqueles que detinham grande produtividade, ou seja, um bom rebanho de vacas e tecnologia na produção (PEDROSO, 2001). O produtor rural era considerado o elo mais frágil da cadeia produtiva do leite, onde para permanecer no mercado (atender a produção mínima estabelecida pela empresa compradora) precisava se especializar (tecnicamente e gerencialmente) tornando-se mais eficiente e produzindo em grande escala. Assim, dois tipos básicos de produtores de leite formaram-se no Brasil, o produtor especializado, e o não especializado, sendo que o especializado se concentra nas principais regiões produtoras do País (Minas Gerais, São Paulo, Rio Grande do Sul e Paraná) (CASTRO et al., 1998; JANK; GALAN, 1998).

Essa nova dinâmica do setor leiteiro, fez com que a produção de leite, o rebanho bovino e a produtividade aumentassem. Entretanto, esse aumento da produtividade, quando comparado aos demais países produtores ainda é baixo. $\mathrm{O}$ aumento da produção no País se deve aos baixos custos relacionados aos fatores climáticos, ambientais, tecnológico e logísticos favoráveis, além disso, houve a implementação de legislações internas para manter o produto com alta qualidade (MAIA et al., 2013; CARVALHO et al., 2007; VILELA, 2017). 
Novos programas e normas relacionados com a produção do leite de vaca no País, adoção de tecnologias, aprimoramento das raças e sanidade, foram sendo implementadas ao longo do tempo. Acerca de algumas normativas, implementaram-se: a Portaria 56, a qual estabeleceu regras para a produção de vários tipos de leite; a Instrução Normativa $\mathrm{n}$ 51, de 18 de setembro de 2002, que busca garantir a segurança alimentar e a qualidade do leite visando a atuação competitiva do Brasil no mercado internacional, visto que o País vinha sofrendo com barreiras ligadas à relação produtor/indústria, à estrutura organizacional, de cunho tecnológico e de caráter institucional; Instrução Normativa $\mathrm{n}$ o 62, do ano de 2011, que tem por objetivo apresentar os requisitos que devem ser observados na produção, na identidade e na qualidade do leite tipo A; e entre outras (MAPA, 2021; CARVALHO et al., 2007; ZOCCAL et al., 2005).

O Ministério de Agricultura, Pecuária e Abastecimento (MAPA) apresentou alguns programas ligados a esse setor, como: Boas Práticas e Bem-estar Animal; Plano de Incentivo à Pecuária Bovina (criado no ano de 2014), conhecido como os programas Mais Leite e Mais Carne; e, Melhoria de Competitividade. Além disso, destacam-se a ação de órgãos (nacionais e estaduais) que auxiliam o produtor de leite, tais como: a Empresa Brasileira de Pesquisas Agropecuárias (EMBRAPA) e a Empresa de Assistência Técnica de Extensão Rural (EMATER) (MAPA, 2021).

Esses benefícios e apoio fornecidos pelo Governo, apontaram, na década de noventa, para uma produção bovino leiteira crescente, inserção no mercado internacional, redução na informalidade e indústrias estáveis (CARVALHO et al., 2007). Essas perspectivas indicadas, podem ser visualizadas nos dias atuais, a produção de leite no Brasil teve um crescimento de $391 \%$ de 1974 para 2019, o número de vacas ordenhas cresceu 50\% nesse mesmo período e, a produtividade, que é ainda considerada baixa, apresentou uma taxa de crescimento de $227 \%$ nesses 45 anos analisados. Dados da USDA (2021) apontam o Brasil como quinto maior produtor mundial de leite, ficando atrás da Índia, Estados Unidos, China e Rússia.

De acordo com dados do Instituto Brasileiro de Geografia e Estatística (IBGE, 2021a), as principais regiões brasileiras que contribuíram para o crescimento da produção total de leite de vaca no País são as Regiões Sudeste, Sul e Centro-Oeste, com destaque para três estados: Minas Gerais, Paraná e Rio Grande do Sul, os quais responderam, conforme retratado na figura 1, por $52 \%$ da produção brasileira de leite em 2019. Salienta-se que esses estados, também, são os mais produtivos. Cabe ressaltar a produtividade leiteira do Rio Grande do Sul (3.610 litros/vaca/ano) é maior que a do Estado de Minas Gerais (3.012 litros/vaca/ano) e está muito acima da média do Brasil (2.142 litros/vaca/ano). 
Figura 1 - Distribuição da produção de leite de vaca nos estados do Brasil em 2019

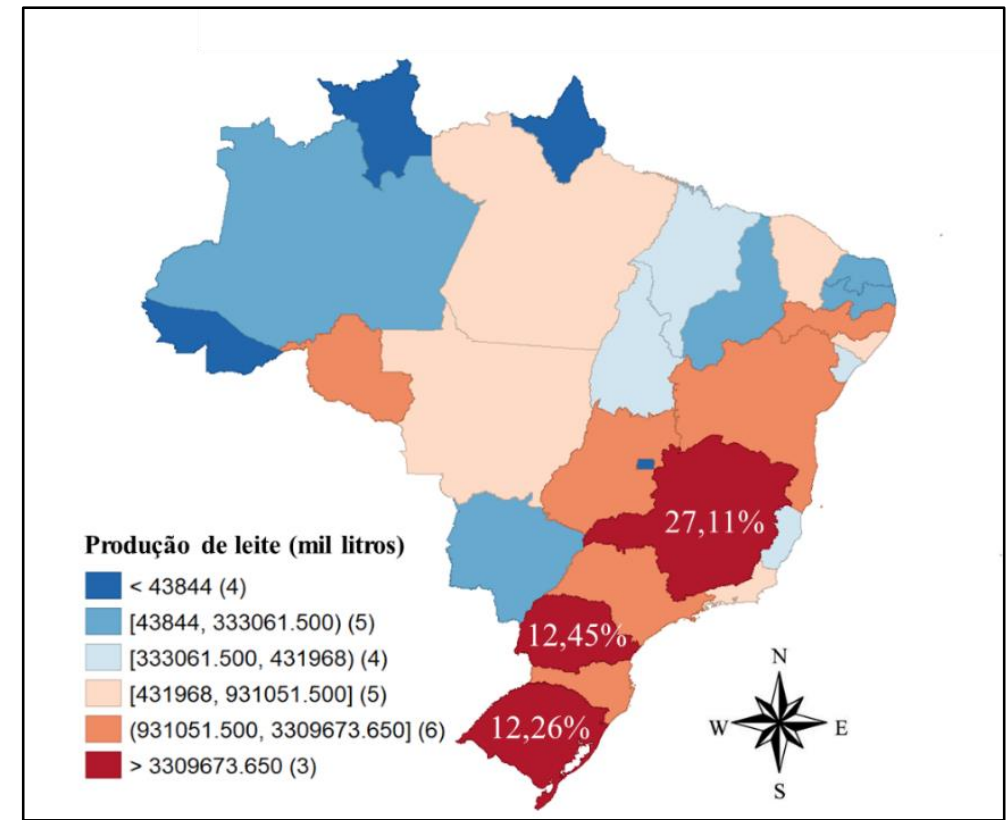

Fonte: Elaborado pelos autores a partir de dados do IBGE (2021a).

O Rio Grande do Sul, conforme já ressaltado, experimentou expressivos ganhos de produtividade nos últimos anos. Para referendar esta afirmação, apresenta-se na figura 2 a produção de leite e o número de vacas ordenhadas. A produção de leite no Rio Grande do Sul é a terceira maior do Brasil, com um volume de 4,27 bilhões de litros, no ano de 2019 (em 1974 era 771 milhões de litros) e, formado por um rebanho de 1.183.152 de vacas ordenhadas (cabeças) (em 1974 era de 821.976 de vacas ordenhadas).

Figura 2 - Produção de leite e números de vacas ordenhadas no Rio Grande do Sul de 1974 até 2019

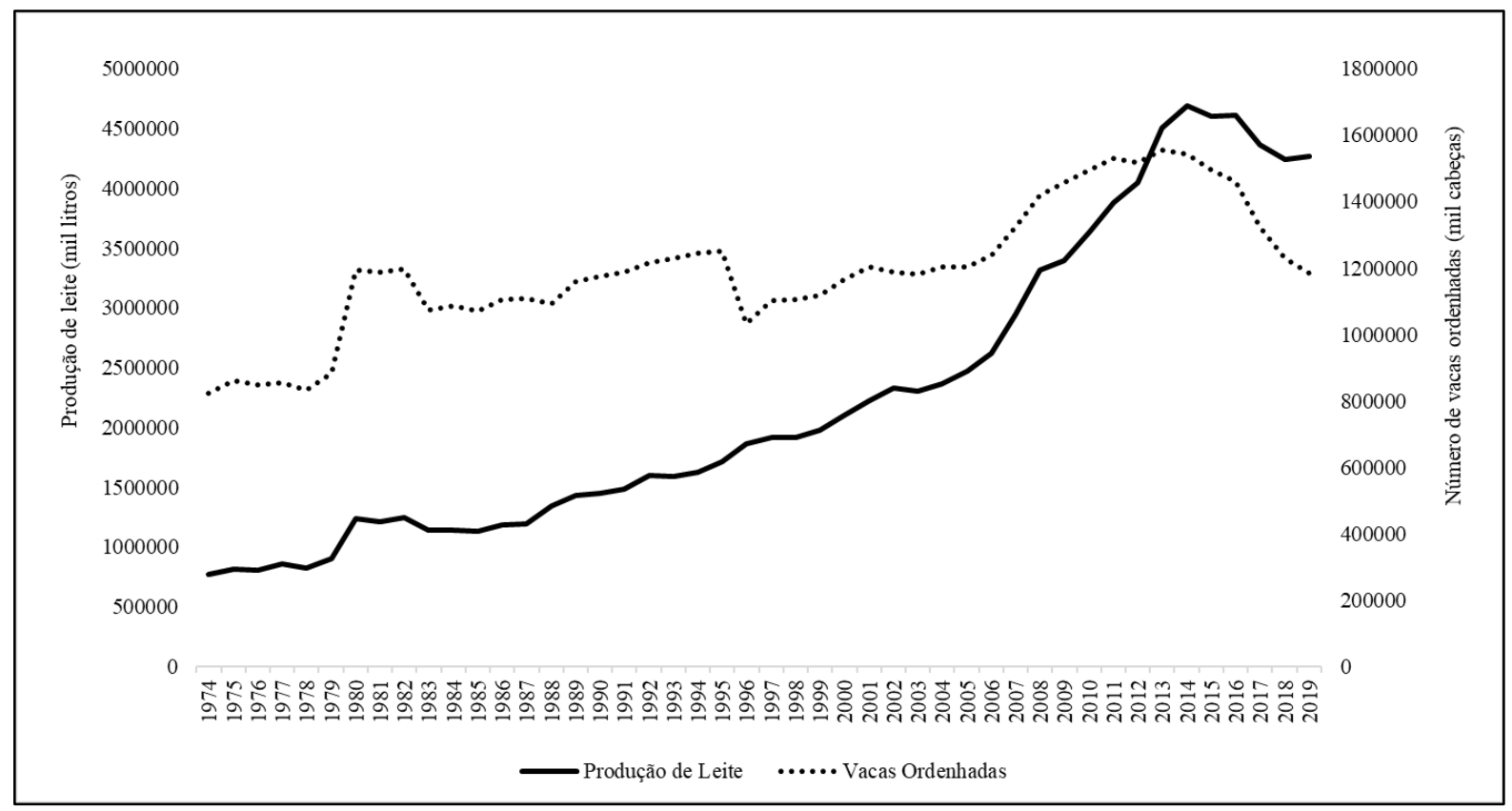

Fonte: Elaborado pelos autores a partir de dados do IBGE (2021a). 
Quanto a performance da sua produtividade, percebe-se uma taxa de crescimento de 284\%, do ano de 1974 para 2019, passando de 939 litros/vaca/ano para 3.610 litros/vaca/ano (IBGE, 2021a). As curvas apresentadas na figura 2 demonstram uma relação inversa entre a produção total de leite que apresenta uma trajetória de crescimento acentuada e o número total de vacas ordenhadas cuja trajetória de crescimento é mais suave, o que sugere o aumento de produtividade por animal ordenhado.

Silva Neto e Basso (2005) salienta que a região que mais produz leite no RS é a região Norte, a qual se beneficiou da grande produção de soja. Para o autor, a partir da década de noventa, o bom desempenho da produção de soja e depois a necessidade de expandir as propriedades (estabelecimentos com área de cultivo pequena) criaram as condições econômicas para que os produtores dessa região investissem em tecnologia na atividade leiteira.

A mesorregião Noroeste Rio-Grandense apresentou a maior produção nacional em 2019, com um volume de 2.868 milhões de litros de leite e uma produtividade de 3.972 litros/vaca/ano (IBGE, 2021a). Maia et al. (2013) e Vilela et al. (2017), evidênciam que boa parte da produção é realizada por grandes produtores, pois nos últimos anos percebeu-se que, aproximadamente, 450 mil estabelecimentos abandonaram a produção de leite, ou seja, a ordenha mecanizada, inseminação artificial e insumos de qualidade, acabaram expulsando os produtores de leite que estavam resistentes a adoção dessas tecnologias.

Assim, dada a importância do setor leiteiro para a economia brasileira e gaúcha e sabendo da heterogeneidade de localizações que ela está presente, faz-se necessário aprofundar estudo sobre sua distribuição geográfica no decorrer dos últimos trinta e nove anos (1980-2019) no estado do Rio Grande do Sul. Diante disso, destina-se a próxima seção para apresentar a metodologia utilizada para analisar a distribuição espacial da produção de leite no Rio Grande do Sul.

\section{Metodologia}

Para atingir o objetivo proposto pela presente pesquisa, procede-se uma análise exploratória de dados espaciais (AEDE). Essa análise é um componente da econometria espacial, a qual vem apresentando grandes avanços no campo econométrico, pois ela incorpora os efeitos espaciais, ou seja, compreende dados (corte transversal ou em painel) e diferentes unidades geográficas. 
Os efeitos espaciais ocorrem de duas formas, por meio da dependência espacial e da heterogeneidade espacial. A dependência espacial, conhecida também como autocorrelação espacial, está relacionada com a interação da produtividade do leite entre diferentes regiões. Por sua vez, a heterogeneidade espacial, se apresenta nas análises devido as diferenças das regiões, ou seja, as regiões tendem a apresentar comportamentos, estruturas e características diferentes umas das outras. O fato de haver heterogeneidade viola a hipótese de homocedasticidade (ALMEIDA, 2012).

Diante disso, para analisar o padrão de comportamento da produção de leite de vaca nos municípios do estado do Rio Grande do Sul, a partir da década de 1980, realiza-se uma análise de cluster. Nesta abordagem, busca-se estimar a associação espacial por meio dos métodos de autocorrelação espacial global ou local e do diagrama de dispersão de I de Moran. A autocorrelação espacial busca mensurar o nível de associação, por meio da matriz de variânciacovariância (equação (1)), dos valores referentes à produtividade do leite nos diferentes municípios ( $i$ e $j$ ).

$$
\begin{gathered}
\operatorname{Cov}\left(P D T L_{i}, P D T L_{j}\right)=E\left(P D T L_{i}, P D T L_{j}\right)+E\left(P D T L_{i}\right)+E\left(P D T L_{j}\right) \\
\neq 0 \quad \text { para } i \neq j
\end{gathered}
$$

em que, $P D T L$ é a produtividade do leite no $i$-ésimo e $j$-ésimo município, respectivamente.

Dado que a matriz de covariância, apresenta dimensão $n \times n$ e contém $n^{2}-n$ elementos, existem duas formas de mensuração da dependência espacial, a geoestatística e a paramétrica. Na presente pesquisa, se utiliza a paramétrica, pois ela é especificada por meio de um arranjo de interações espaciais municipais, ou seja, é uma matriz de ponderação espacial $(W)$.

A matriz de ponderação, de acordo com Anselin e Bera (1998), é formada pelas interações das regiões, as quais são denominadas de peso espacial $\left(w_{i j}\right)$ e que podem ser mensuradas pela proximidade (fronteira física) entre as regiões. Assim, a matriz $W$ da presente pesquisa, é construída com base na contiguidade, em que $w_{i j}=1$, representa os municípios vizinhos e $w_{i j}=$ 0 quando os municípios $i$ e $j$ não são vizinhos.

Para identificar se um município é vizinho de outro, utiliza-se a matriz de ponderação. Existem alguns tipos de convenções para esta finalidade, como representado na figura 3, as quais são parecidas com o jogo de xadrez. A figura 3a (rainha) considera as fronteiras físicas e os vértices e a figura $3 \mathrm{~b}$ (torre) contempla apenas as fronteiras físicas. 
Figura 3 - Convenções de contiguidade.

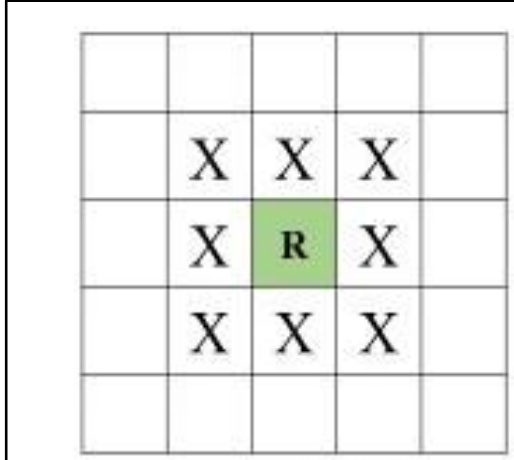

a) Rainha

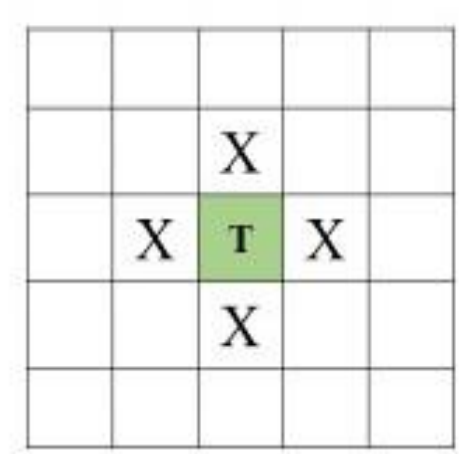

b) Torre

Fonte: Elaborado pelos autores com base em Almeida (2012).

Diante disso, para a realização da análise de cluster, são testados os dois tipos de convenções e escolhida uma das matrizes de ponderação espacial. Após escolhida a matriz, realiza-se uma análise exploratória buscando conhecer os dados, e identificar se há dependência espacial e se há heterogeneidade espacial, as quais são necessárias para medir a presença de autocorrelação espacial global e local e serão apresentadas mais detalhadamente nas próximas subseções.

\subsection{Autocorrelação Espacial Global}

Para identificar o nível de associação espacial, ou seja, formação de clusters, faz-se necessário identificar se as regiões apresentam autocorrelação, pois caso elas apresentem aleatoriedade, a análise espacial não se faz necessária. Parte-se, então, da averiguação da existência ou não da aleatoriedade nos dados sobre produtividade de leite bovino no Rio Grande do Sul.

Para examinar a aleatoriedade (valores de uma variável numa localidade não dependem dos valores dessa variável na localidade vizinha), realiza-se um teste estatístico para obter o coeficiente de autocorrelação espacial, conhecido como índice I de Moran, apresentado na equação (2). Esta estatística, além de examinar se há aleatoriedade, fornece, por meio de sua magnitude, o quanto as regiões estão autocorrelacionadas, valores próximos de 1 apontam maior concentração, e valores próximos de -1 indicam menor concentração (dados dispersos) (ALMEIDA; PEROBELLI; FERREIRA, 2008; ANSELIN; BERA, 1998).

$$
I=\frac{n}{S_{o}} \frac{\sum_{i} \sum_{j} w_{i j} P D T L_{i} P D T L_{j}}{\sum_{i=1}^{n} P D T L_{i}^{2}}
$$


em que, $n$ é o número de municípios, PDTL corresponde aos valores da produtividade padronizadas, WPDTL são os valores médios da produtividade padronizada nos vizinhos (definidos pela matriz de ponderação $W$ ). Além disso, $w_{i j}$ é o peso espacial, ou seja, a relação espacial entre a região $i$ e a $j$, e, o $S_{o}$ é somatório de todos os elementos da matriz $W$.

A hipótese nula a ser testada é a da aleatoriedade, o I de Moran apresenta um valor esperado de $E(I)=-[1 /(n-1)]$, o qual demonstra se há autocorrelação positiva (valores maiores que o valor esperado) ou negativa (valores menores que valor esperado). A autocorrelação positiva do I de Moran indica que os dados são concentrados, ou seja, valores altos (baixos) de uma variável tendem a estar próximos de regiões que apresentam valores altos (baixos). Já a autocorrelação negativa, aponta para uma dissimilaridade entre os dados, ou seja, valores altos (baixos) tendem a estar concentrados próximos a valores baixos (altos) (ALMEIDA, 2012).

Após a realização do I de Moran faz-se necessário verificar se a estatística calculada é estatisticamente significativa, para tanto, utiliza-se a equação (3), pressupondo a hipótese da normalidade.

$$
Z(I)=\frac{[I-E(I)]}{D P(I)}
$$

em que, $E(I)$ é o valor esperado e $D P(I)$ é o desvio padrão teórico, ambos relacionados com o índice (I).

Dada a relevância da estrutura regional, no próximo tópico busca-se analisar a autocorrelação espacial local, pois a estatística I de Moran global não comtempla observar as correlações locais.

\subsection{Autocorrelação Espacial Local}

Para analisar como o conjunto de dados no todo está agrupado, utiliza-se a autocorrelação espacial global. Já autocorrelação espacial local é indicada para visualizar, especificamente, as informações (se há clusters) de cada município, ou seja, se os municípios com alta (baixa) produtividade de leite de vaca estão próximos de um grupo de municípios com valores altos (baixos) de produtividade.

Para Almeida (2012) uma das formas de identificar, estatisticamente, a autocorrelação espacial local é pelo índice de Moran local (I de Moran local). Esse índice captura o nível de 
associação espacial local, o qual é conhecido como local indicator of spatial association (LISA) e pode ser calculado por meio da equação (4).

$$
I_{i}=P D T L_{i} \sum_{j=1}^{J} w_{i j} P D T L_{j}
$$

em que, $I_{i}$ é o coeficiente do I de Moran, $P D T L_{i}$ e $P D T L_{j}$ corresponde aos valores da produtividade de leite padronizadas para diferentes municípios. Além disso, o somatório dos $I_{i}$ equivale ao Índice de Moran global.

Para testar a hipótese nula de aleatoriedade, utiliza-se o pressuposto de normalidade, em que o valor esperado I de Moran local pode ser obtido pela equação (5) (ANSELIN; BERA, 1998).

$$
E\left(I_{i}\right)=\frac{-w_{i}}{n-1}
$$

onde, $w_{i}$ é a soma dos pesos espaciais da matriz $W$.

Para uma melhor visualização dos resultados obtidos na pesquisa, pode-se utilizar os mapas de clusters LISA. Esses mapas combinam as informações do diagrama de dispersão com as estatísticas de significância. O diagrama de dispersão, também, utilizado na presente pesquisa, é apresentado mais detalhadamente no próximo item.

\section{3 "I de Moran": diagramas de dispersão da produtividade do leite}

Além da visualização do nível de autocorrelação pelo "I de Moran", é possível analisar pelo diagrama de dispersão, o qual é uma abordagem alternativa que proporciona melhor visualização da autocorrelação espacial e indica o tipo de associação linear espacial que o munícipio pertence.

O diagrama de dispersão de Moran, de acordo com Almeida (2012), mostra a correlação linear da variável em análise (eixo horizontal - PRDTL) e sua defasagem espacial (eixo vertical $\left.W_{P R D T L}\right)$. Para tal análise utiliza-se as variáveis padronizadas, tornando-as $z$ e $W z$, as quais apresentaram média zero e variância unitária.

Assim sendo, o diagrama de dispersão pode ser visualizado na forma de um gráfico como representado na figura 4. Assim, o coeficiente autocorrelação ("I de Moran") é obtido por meio da inclinação da curva de regressão de Wz contra $z$. O sinal do coeficiente (+/-) indica se há autocorrelação positiva ou negativa. 
Figura 4 - Exemplo de um diagrama de dispersão de Moran

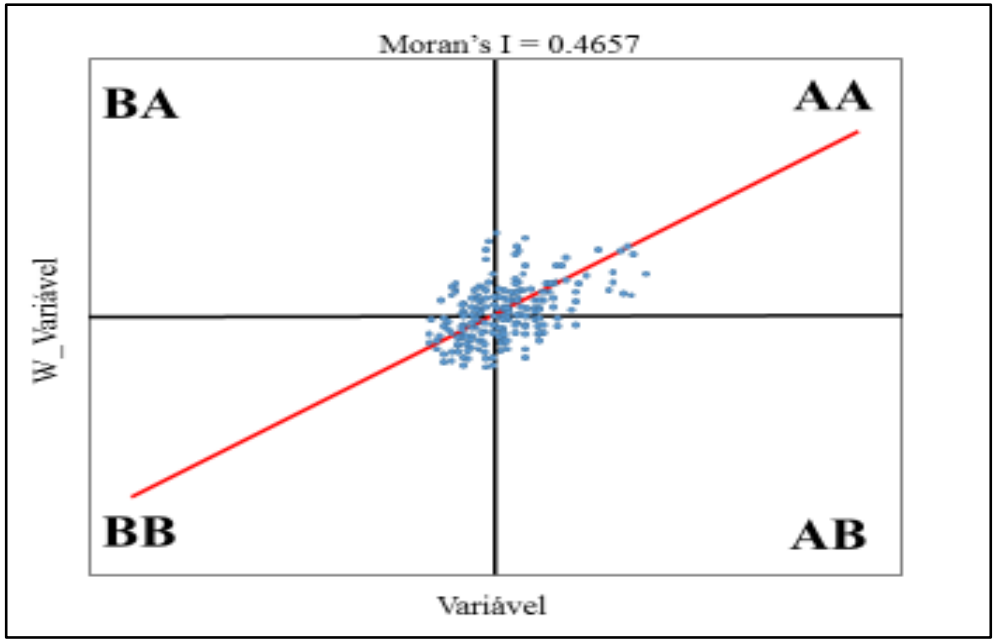

Fonte: Elaborado pelos autores com base em Almeida (2012).

Desta forma, ao se analisar a figura 4, percebe-se quatro quadrantes, os quais representam diferentes tipos de associação linear espacial, que de acordo com Almeida, Perobelli e Ferreira (2008), podem ser especificados como:

- O quadrante baixo-alto (BA) indica que os municípios com valores baixos de produtividade de leite são rodeados por municípios com valores altos dessa mesma variável.

- O quadrante alto-alto (AA) apresenta municípios com valores altos e que estão circundados por municípios com altos valores de produtividade de leite.

- O quadrante baixo-baixo (BB) é composto por um grupo de regiões que têm valores baixos de produtividade de leite e seus vizinhos apresentam valores baixos também.

- O quadrante alto-baixo $(A B)$ refere-se a localidades em que os valores de produtividade de leite são altos, porém os valores de seus vizinhos são baixos.

Em resumo, os municípios que se localizarem nos quadrantes $A A$ e $B B$ apresentam associação espacial positiva, ou seja, os valores da produtividade de leite dos municípios são similares. Já, os quadrantes $A B$ e BA indicam associação espacial negativa, em que os valores da produtividade de leite dos municípios são dissimilares.

\subsection{Base e fonte dos dados}

A fim de avaliar o padrão de comportamento da produtividade de leite bovino dos municípios do estado do Rio Grande do Sul a partir da década de 1980, utilizou-se dados referentes a produtividade. Esses dados foram construídos por meio da razão entre a média de 
produção de leite litros/ano e a média do número de vacas ordenhadas, por década e para o ano de $2019^{7}$.

As informações sobre as variáveis vacas ordenhadas ( $n$ - de cabeças) e produção de leite (mil litros) foram obtidas no site do Instituto Brasileiro de Geografia e Estatística (IBGE), mais especificamente, na pesquisa da pecuária municipal. Esses dados correspondem aos anos de 1979, 1980, 1981, 1989, 1990, 1991, 1999, 2000, 2001, 2009, 2010, 2011 e 2019, e referem-se a amostra de 497 municípios do estado do Rio Grande do Sul, mas devido a utilização do shapefile 2007-2008 ${ }^{8}$, o total de municípios analisados é 496.

Inicialmente, realizou-se a média da produção entre o ano que antecede a década, ano inicial da década, e ano que sucede a década, para, assim, se obter um valor médio para cada década (1980, 1990, 2000, 2010), por exemplo, fez-se a média da produção para 1979, 1980 e 1981, para se construir uma informação mais suavizada relativa à pecuária leiteira no início da década de 1980. De igual maneira, se calculou as informações para o início da década de 90, início dos anos 2000 e início da primeira década de 2010. A exceção é o ano de 2019, em que a produtividade do leite foi calculada com os valores específicos do ano.

Para a realização da análise exploratória espacial, faz-se necessário atribuir a localização geográfica (georreferências) de cada município gaúcho produtor de leite. Para a presente pesquisa, utilizou-se os geocódigos e o shapefile da Fundação de Economia e Estatística (FEE), referentes ao ano de 2007-2008. Além disso, a construção dos mapas de cluster e de distribuição espacial ocorreu por meio dos softwares GeoDa e Qgis 3.0.

\section{Resultados e discussões}

A presente seção analisa o padrão de comportamento da produtividade de leite de vaca dos municípios do estado do Rio Grande do Sul em distintos retratos, constituídos a partir da década de 1980. Para caracterizar como a produtividade se encontrava nas últimas décadas, apresenta-se, na tabela 1, alguns indicadores de estatística descritiva para a produtividade de leite do Rio Grande do Sul. Nesta Tabela, destaca-se a média, mínimo, máximo e desvio padrão, relacionados à produtividade leiteira gaúcha para os anos de 1980, 1990, 2000, 2010 e 2019.

\footnotetext{
${ }^{7}$ Ano da última atualização de dados referentes a produção de leite por município.

${ }^{8}$ O shapefile 2007-2008 não contempla o município de Pinto Bandeira, pois ele foi fundado no ano de 2013 (FEE, 2018).
} 
Percebe-se que com o passar dos anos, a média de produtividade de leite bovino no estado aumentou 590\%, passando de 480 litros/vaca/ano em 1980 para 3.312 mil litros/vacas/ano em 2019. Isso decorre, conforme apontado por Resende (2016), Vilela et al. (2016) e Maia et al. (2013), não só pelo aumento do número de vacas em ordenha, mas pela implementação de tecnologia na produção (manejo, tratamento do solo (pastagens), máquinas (tanques de resfriamento, ordenha mecanizada) e insumos de qualidade).

Denota-se, também na Tabela 1, que os desvios padrão da produtividade de leite para os anos em análise são grandes, indicando que há dispersão dos valores em relação à média, ou seja, há uma parcela de municípios que experimenta alta produtividade leiteira e outros com baixíssima produtividade. Isso fica mais claro observando que a produtividade mínima que alguns municípios obtiveram foi de 0 litros/vaca/ano, ou seja, não apresentaram produção, entretanto, alguns municípios apresentam elevada produtividade, como Fortaleza dos Valos (RS) que foi 5.580 mil litros/vaca/ano em 2010.

O aumento do desvio padrão se deve a grande concentração de alta produtividade em algumas regiões do RS, enquanto outras apresentam baixa produtividade, o que ajuda a explicar associação linear espacial do tipo alto-alto e baixo-baixo. Ou seja, a proximidade dos municípios com produtividade alta em uma região específica, enquanto em outras regiões tem-se a proximidade de municípios com baixa produtividade.

Quando se considera os municípios com maior produtividade de leite bovino, nota-se importantes avanços tecnológicos nessa atividade, já que ela passa de cerca de 3 mil litros/vaca/ano para quase $7 \mathrm{mil}$ litros/vaca/ano. Em quase quatro décadas a produtividade leiteira gaúcha mais que dobrou. Cabe ressaltar, que a maior produtividade alcançada no estado do Rio Grande do Sul foi em 2019 com 7.237 litros/vaca/ano no município de Quinze de Novembro.

Tabela 1 - Estatística descritiva da produtividade de leite de vaca do Rio Grande do Sul

\begin{tabular}{llllll}
\hline & $\mathbf{1 9 8 0}$ & $\mathbf{1 9 9 0}$ & $\mathbf{2 0 0 0}$ & $\mathbf{2 0 1 0}$ & $\mathbf{2 0 1 9}$ \\
\hline Média & 480 & 845 & 1.749 & 2.271 & 3.312 \\
\hline Desvio Padrão & 572 & 664 & 654 & 1.092 & 1.487 \\
\hline Mínimo & 0 & 0 & 120 & 0 & 0.333 \\
\hline Máximo & 2.736 & 2.593 & 4.385 & 5.580 & 7.237
\end{tabular}

Fonte: Elaborado pelos autores a partir de dados do IBGE (2021a). 
De maneira geral, a produtividade do estado do RS é alta comparada à média do País (2.142 litros/vaca/ano) e dos demais estados produtores, mas quando se compara com os principais países produtores de leite do mundo (4.569 litros/vaca/ano Nova Zelândia, 7.050 litros/vaca/ano Argentina, 10.290 litros/vaca/ano Canadá, 10.775 litros/vaca/ano Estados Unidos), percebe-se que sua produtividade é baixa (USDA, 2021). Esse fato é reflexo de que a produção de leite em muitos estabelecimentos agropecuários é atividade secundária e alguns produtores ainda se encontram em fase de especialização (CASTRO et al., 1998; IBGE, 2021a; VILELA et al., 2017). Corrobora, também, com as informações da tabela 1, o que Fernandes (1995) e Resende (2016) apontam sobre a produção leiteira gaúcha, que a produtividade aumentou significativamente devido aos programas de estímulo aos produtores (fornecidos pelas indústrias) e pela modernização nos fatores de produção, que contribuíram para a redução dos custos de produção.

Após essa breve análise sobre alguns indicadores, verifica-se se os municípios guardam alguma semelhança entre si, ou seja, se os municípios apresentam produtividade de leite de vaca similares ou dissimilares aos seus vizinhos. Para tanto, fez-se esse diagnóstico por meio do I de Moran global (apresentado na subseção 3.1), sendo estas estatísticas para cada década apresentada na figura 2. É possível visualizar que para todas as décadas em análise há autocorrelação espacial positiva (municípios com produtividade alta estão rodeados por municípios com produtividade alta e vice-versa), dado que o valor esperado do I de Moran foi de $E(I)=-0,00202$. Além disso, percebe-se que três convenções refutam a hipótese nula de aleatoriedade, mas na presente pesquisa utiliza-se a convenção Rainha de grau 1, visto que ela indica melhor autocorrelação espacial entre os municípios e possibilita analisar todos os vizinhos que circundam os municípios.

Tabela 2 - Índice de Moran para produtividade de leite de vaca

\begin{tabular}{llllll}
\hline Convenção & 1980 & 1990 & 2000 & 2010 & 2019 \\
\hline Rainha 1 & $0.1223^{* * *}$ & $0.0741^{* * *}$ & $0.5789^{* * *}$ & $0.6744^{* * *}$ & $0.5804^{* * *}$ \\
\hline Rainha 2 & 0.0206 & $0.0255^{*}$ & $0.3704^{* * *}$ & $0.5265^{* * *}$ & $0.4192^{* * *}$ \\
\hline Torre & $0.1182^{* * *}$ & $0.0750^{* * *}$ & $0.5760^{* * *}$ & $0.6752^{* * *}$ & $0.4189^{* * *}$
\end{tabular}

Fonte: Elaborado pelos autores a partir de dados do IBGE (2021a).

*** Estatisticamente significativos a $1 \%$.

Buscando analisar estatisticamente informações geográficas da produtividade de leite bovino no estado do Rio Grande do Sul, em 1980, tem-se a figura 5. Essa apresenta a distribuição 
espacial da produtividade (a), o índice de Moran (b) e o mapa de clusters (c). Conforme está retratado, na década de 1980, a produtividade de leite no estado do RS era pequena e estava concentrada entre as regiões Metropolitana de Porto Alegre e Centro-Ocidental Rio-Grandense. Além disso, é possível visualizar que há 265 municípios com produtividade abaixo de 365 litros/vaca/ano.

Outro ponto a ser destacado é que o índice de Moran indica autocorrelação espacial positiva (0.12229). Porém, como pode ser visualizado no mapa de clusters (c), existem muitos municípios não significantes, ou seja, municípios que não se encontram em nenhum agrupamento, pois a produtividade é dissimilar estatisticamente, em relação à média dos demais municípios; e apenas um cluster bem definido (alto-alto). Nesse cluster os municípios que obtiveram valores altos de produtividade de leite estão rodeados por municípios que, também, obtiveram valores altos, sendo que eles, estão localizados na faixa de maior produtividade no estado, na década de 1980 (Figura 5 (a)).

Figura 5 - Distribuição, índice de Moran e mapa de clusters da produtividade de leite de vaca do Rio Grande do Sul, para o ano de 1980

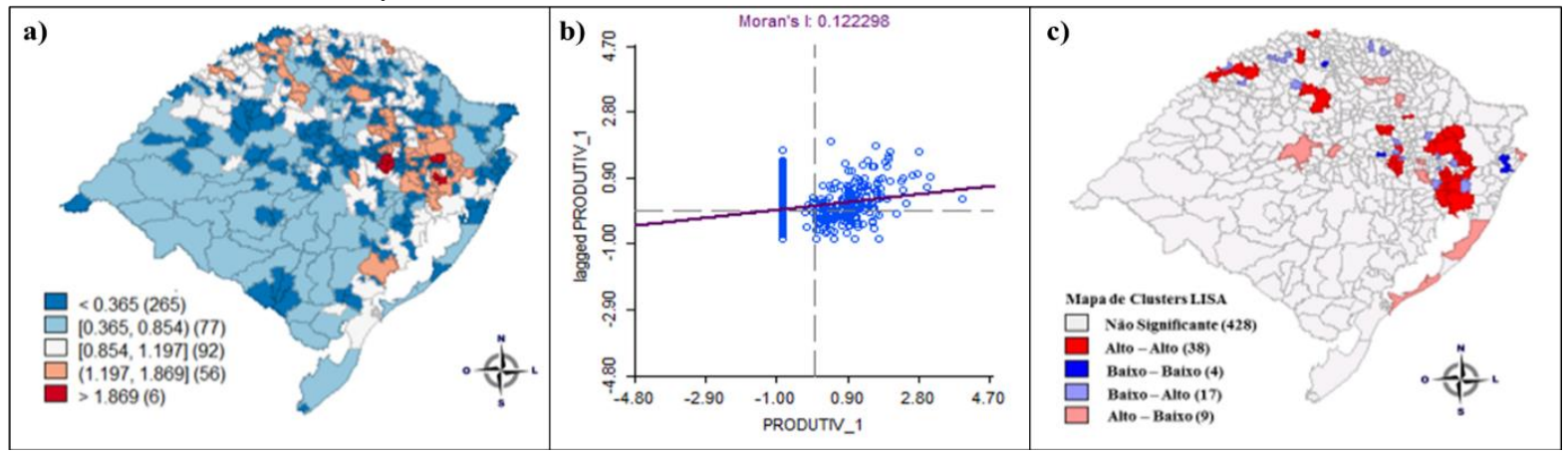

Fonte: Elaborado pelos autores a partir de dados do IBGE (2021a).

A produção de leite bovino no estado do RS, entre 1980 e 1990, apresentou baixas taxas de crescimento, pois era atividade secundária para os produtores, tinha baixo nível tecnológico, alta sazonalidade, baixa qualidade do leite, falta de especialização, pouco crédito e incentivo ao produtor. Além disso, a maior parte da produção situava-se na região Metropolitana de Porto Alegre (FERNANDES, 1995; JANK; GALAN, 1998).

Pedroso (2001) ressalta que a economia brasileira, nos anos oitenta, passava por uma crise econômico-financeira, o que provocou um período de atraso tecnológico e perdas de competitividade da cadeia leiteira. Esse período somente foi superado no final dos anos 1980, quando o consumo brasileiro de leite começou a aumentar com as implementações de planos econômicos de controle do processo inflacionário. 
No ano de 1990, como indica a figura 6 , a produtividade de leite na média aumentou e estava mais presente no estado, mas principalmente, nas regiões Noroeste Rio-Grandense, Centro-Ocidental Rio-Grandense e Metropolitana de Porto Alegre. Nota-se que o número de munícipios com produtividade baixa reduziu em comparação a década de 1980, passando para 164 municípios com produtividade menor que 406 litros/vaca/ano. O índice de Moran (b) indica autocorrelação espacial positiva e, a figura 6 (c), evidencia a formação de dois clusters alto-alto (vermelho). Um cluster localizado mais próximo da região Noroeste e outro na região Metropolitana de Porto Alegre, ambos indicam que os municípios com altos valores de produtividade estão circundados de municípios com valores altos.

Figura 6 - Distribuição, índice de Moran e mapa de clusters da produtividade de leite de vaca do Rio Grande do Sul, para o ano de 1990

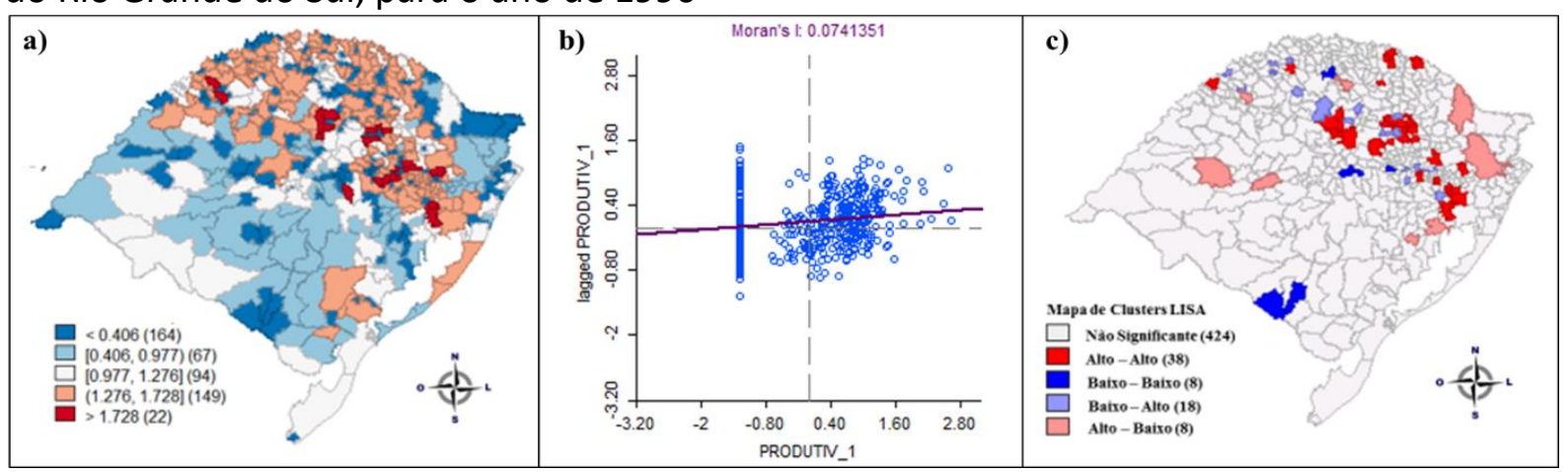

Fonte: Elaborado pelos autores a partir de dados do IBGE (2021a).

Entre 1986 e 1994 houve expansão da produção de leite bovino para as regiões do Planalto Médio e Alto Uruguai, ao passo que as regiões tradicionais na produção: a da Serra e da Depressão Central experimentaram decréscimo nos patamares de produção. Ressalta-se que as regiões Planalto Médio e Alto Uruguai começaram a produzir leite, em razão de haver pressão imobiliária sobre as bacias leiteira, levando-as a se afastarem dos grandes centros urbanos (Porto Alegre). A região Metropolitana, no decorrer dos anos, reduziu sua produção de leite, já que as indústrias de processamento do leite acompanhavam o deslocamento do complexo leiteiro (CASTRO et al., 1998).

Na década de 1990, as bacias leiteiras encontravam-se entre nos estados de Minas Gerais, São Paulo, Paraná e Rio Grande do Sul. Por mais que a média de produtividade dos rebanhos era considerada baixa, 1.500 litros/vaca/ano, notava-se algumas mudanças, como coleta a granel, normas de produção, sistema de fiscalização, indícios de políticas públicas e aumento no número de produtores especializados. O setor leiteiro estava começando a reagir com o aumento da 
produção e produtividade e redução nos custos (FERNANDES, 1995; JANK; GALAN, 1998; PEDROSO, 2001).

Para avaliar como as transformações da produtividade do leite do Rio Grande do Sul esteve distribuída geograficamente, em 2000, elaborou-se a figura 7. Verifica-se, primeiro, que distribuição espacial da produtividade mais alta, figura 7 (a), desloca-se para a região Noroeste Rio-Grandense e segundo, redução no número de municípios com produtividade baixa. Observase ainda, que o I de Moran, na década de 2000, vis-à-vis as décadas de 1990 e 1980 está melhor, ou seja, existe maior autocorrelação espacial entre os municípios, sendo possível visualizar pelo mapa de cluster na figura 7(c). Esse mapa (c) retrata a formação de cinco cluster, três do tipo baixo-baixo (azul) e dois do tipo alto-alto (vermelho). Os clusters do tipo baixo-baixo são os municípios que apresentam produtividade baixa e seus vizinhos também têm produtividade baixa, os quais se encontram localizados nas regiões Sudoeste, Sudeste e Nordeste RioGrandense. Já os clusters alto-alto, com os municípios apresentando produtividade alta e seus vizinhos também, estão locados nas regiões Noroeste Rio-Grandense (cluster composto por mais municípios) e Centro-Oriental Rio-Grandense.

Figura 6 - Distribuição, índice de Moran e mapa de clusters da produtividade de leite de vaca do Rio Grande do Sul, para o ano de 1990

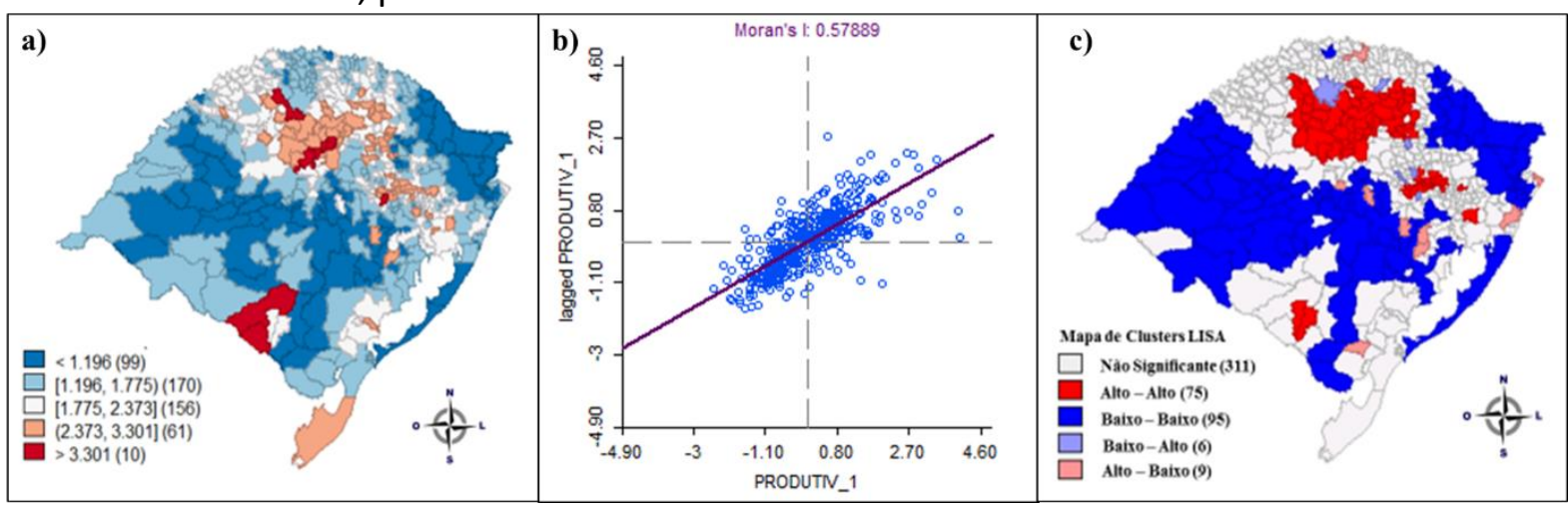

Fonte: Elaborado pelos autores a partir de dados do IBGE (2021a).

A passagem da década de 1990 para 2000 foi marcada por diversos acontecimentos que atingiram diretamente a produção de leite de vaca no Rio Grande do Sul. Fim da política de tabelamento dos preços, abertura comercial, participação no Bloco Econômico Mercosul, implantação do Plano Real, medidas essas que aproximavam o Brasil da globalização e ao mesmo tempo despertava a necessidade de atualização tecnológica, produtos de melhor qualidade e um mercado altamente competitivo (CASTRO et al., 1998). Entretanto, alguns pontos positivos em relação aos anos anteriores já eram possíveis de serem notados, tais como o aumento da produtividade, reduções nos custos de transporte e resfriamento de leite, qualidade da matéria- 
prima e preços pagos ao produtor de acordo com o volume produzido (JANK; GALAN, 1998). Esses argumentos ajudam a explicar a conformação obtida na figura 7.

Na figura 8 apresenta-se a distribuição espacial, índice de Moran e mapa de clusters da produtividade de leite do Rio Grande do Sul para o ano de 2010. Deflagra-se, inicialmente na figura (a), que a produtividade mais alta concentrou-se na região Noroeste Rio-Grandense. Utilizando a convenção rainha, assim como nas demais análises, constatou-se autocorrelação espacial positiva pelo I de Moran (b).

Dado a existência de autocorrelação espacial, o mapa de clusters (c) aponta para quatro clusters, três do tipo baixo-baixo, posicionados nas regiões Sudoeste Rio-Grandense, Centro RioGrandense e Metropolitana de Porto Alegre. Em contrapartida, o cluster alto-alto está localizado na região Noroeste Rio-Grandense, destacando que os municípios com produtividade alta, estão cercados por municípios que apresentam alta produtividade.

Figura 8 - Distribuição, índice de Moran e mapa de clusters da produtividade de leite de vaca do Rio Grande do Sul, para o ano de 2010

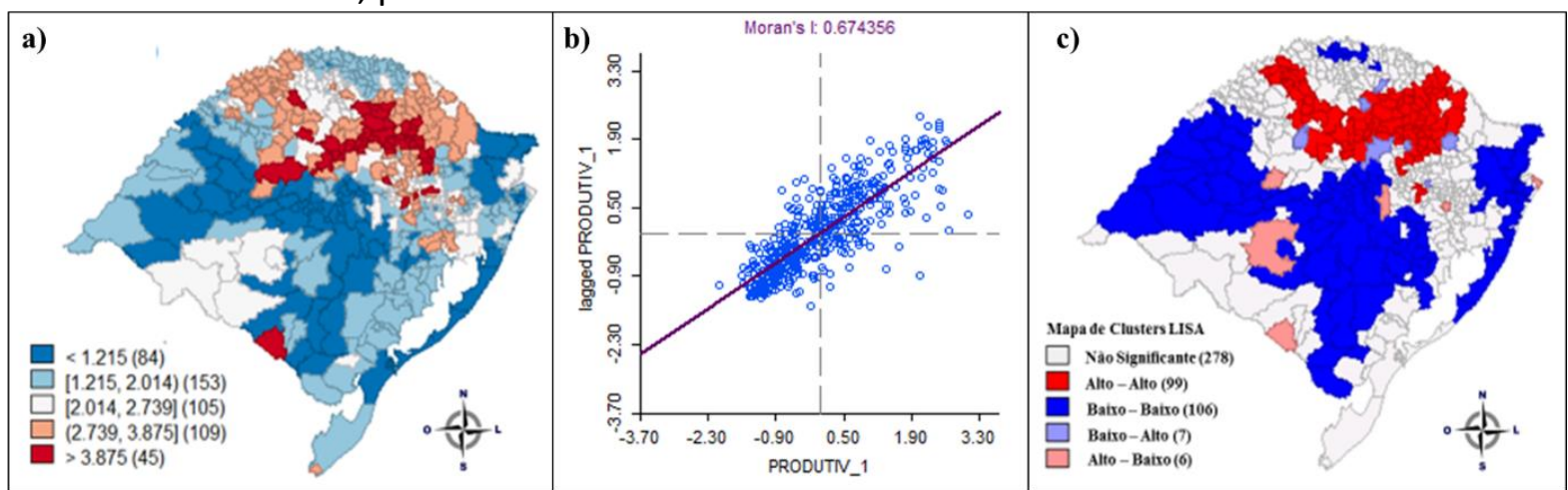

Fonte: Elaborado pelos autores a partir de dados do IBGE (2021a).

Quando se analisa a distribuição espacial da produção de leite bovino percebe-se, que após 2000 , as regiões tradicionais na produção de leite foram sendo desativadas e novas regiões (Noroeste Rio-Grandense), com melhores tecnologias e rebanhos, foram incorporando os produtores e as indústrias do complexo leiteiro (FERNANDES, 1995).

Verifica-se, também, que o Rio Grande do Sul apresenta uma heterogeneidade de produtividade, ou seja, regiões com alta produtividade e outras com baixa produtividade, isso se deve aos diferentes tipos de sistema de produção (à pasto e semiconfinado) e a adoção de tecnologias avançadas (CARVALHO et al., 2007). É ressaltado na literatura que a produção de leite, bem como a produtividade evoluiu de forma desigual no Rio Grande do Sul. Existe uma concentração de municípios produtores de leite na região Norte do estado, as quais apresentam taxas crescentes de especialização na produção, devido ao ganho de eficiência, ao passo que se 
verifica redução na produção dos municípios localizados nas mesorregiões Metropolitana de Porto Alegre e Centro (MARION FILHO; OLIVEIRA, 2011; VILELA et al., 2016).

Como forma de analisar o comportamento espacial da produtividade de leite no RS, em 2019, apresenta-se a figura 9. Essa ilustra como a produtividade de leite está distribuída ao longo do território Rio-Grandense, bem como os clusters presentes no estado em 2019. Percebe-se que a alta produtividade de leite, figura 9 (a), está presente na região Noroeste Rio-Grandense, assim como ocorreu na década de 2000. Além disso, nota-se que há produtividade elevada em alguns municípios localizados na faixa litorânea e no Sudeste Rio-Grandense.

Observando a constatação de autocorrelação espacial positiva pelo "I de Moran", figura 9 (b). Essa figura aponta para quatro clusters, três do tipo baixo-baixo e um alto-alto. O cluster do tipo alto-alto concentra-se na região Noroeste Rio-Grandense. Por outro lado, os clusters baixo-baixo, se encontram localizados nas regiões Sudoeste, Centro e Nordeste Rio-Grandense. Clusters esses, que estão se consolidando desde a década de 2000.

Figura 9 - Distribuição, índice de Moran e mapa de clusters da produtividade de leite de vaca do Rio Grande do Sul, para o ano de 2019

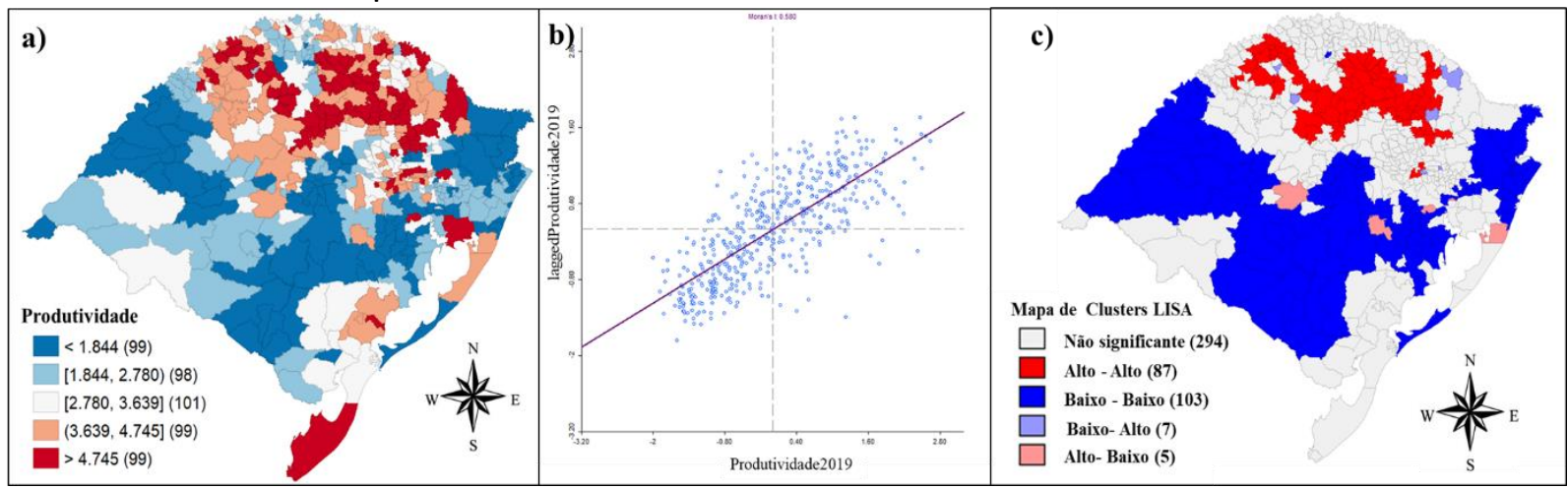

Fonte: Elaborado pelos autores a partir de dados do IBGE (2021a).

Portanto, com o fim da política de tabelamento dos preços, abertura comercial, participação no Bloco Econômico Mercosul, implantação do Plano Real e outras mudanças econômicas ocorridas nos anos noventa, levou o complexo leiteiro gaúcho a se adaptar, com a implementação de novas tecnologias na produção, para se tornar competitivo e continuar subsistindo. Com a análise dos mapas de distribuição espacial da produtividade de leite e da formação dos clusters foi possível identificar justamente isso, que a produtividade de leite no estado do Rio Grande do Sul, realmente, passou por muitas transformações, sendo que as maiores mudanças ocorreram entre as décadas de 1990 e 2000, principalmente, com o deslocamento da produção de leite de vaca da região Metropolitana de Porto Alegre para a região Noroeste e, a existência de grupos de municípios com alta produtividade e grupos com 
baixa produtividade no estado, ou seja, presença de heterogeneidade da produtividade de leite no RS.

Ao longo dessas quase quatro décadas em análise, foi possível observar que existe menos produtores de leite, porém com produtividades superiores às de meados dos anos oitenta e grandes empresas que alavancaram a produção no estado, especialmente, na região Norte do RS (JANK; GALAN, 1998). Além disso, tem-se a grande heterogeneidade como característica do volume produzido de leite, do tipo de produtor, do rebanho, da estrutura da propriedade, do sistema de produção e das tecnologias adotadas. Sendo que o desempenho do estado na produção de leite está relacionado aos subsídios, as inovações tecnológicas, ao padrão genético, as pastagens, ao modo de manejo e sanidade com o rebanho (CARVALHO et al., 2007; RESENDE, 2016). Vilela et al. (2017) destaca que o complexo leiteiro se tornou mais organizado, em que os elos da cadeia leiteira discutem conjuntamente os desafios e oportunidades do mercado que estão inseridos.

\section{Considerações finais}

A presente pesquisa objetivou analisar o padrão de comportamento espacial da produtividade de leite bovino no estado do Rio Grande do Sul a partir da década de 1980, por meio do ferramental Análise Exploratória de Dados Espaciais (AEDE) utilizando dados sobre a produtividade. Os resultados dessas mudanças apontam que a produtividade de leite do Rio Grande do Sul apresentou taxas crescentes no período analisado. Entretanto, essa produtividade deslocou-se entre as regiões do estado, passando da região Metropolitana de Porto Alegre (1980) para a região Noroeste e Nordeste Rio-Grandense (2019).

Quando se analisou o índice de Moran, percebeu-se que houve autocorrelação espacial positiva entre os municípios do estado, evidenciando a formação de clusters, na região Noroeste Rio-Grandense do tipo alto-alto, ou seja, municípios com produtividade alta estão próximos de municípios com alta produtividade e, na região Sudoeste obteve-se um cluster do tipo baixobaixo, o que significa municípios com produtividade baixa estão circundados por municípios vizinhos com baixa produtividade.

Pode-se concluir que houve crescente especialização e concentração da produtividade de leite bovino no Norte do estado a partir da década de 2000. Além disso, denota-se que a produtividade de leite se encontra distribuída geograficamente de forma heterogênea entre os municípios do Rio Grande do Sul, dado que houve o crescimento desigual dessa atividade entre 
as regiões. Grande parte dos autores evidenciados no decorrer do presente estudo, apontam o avanço tecnológico, a mecanização e a busca constante por especialização como principais fatores do aumento da produtividade.

A análise exploratória de dados espaciais da produtividade de leite de vaca permitiu observar de que forma a produtividade de leite se comportou no decorrer das décadas de 1980, 1990, 2000, 2010 e 2019 no Rio Grande do Sul. Assim, foi identificado deslocamentos geográficos na produtividade e a formação de novos grupos de municípios com alta e baixa produtividade, fornecendo informações para futuros estudos analisarem mais profundamente as diferenças entre os produtores de leite das regiões Nordeste e Sudoeste do Rio Grande do Sul e para empresas do setor leiteiro investirem em instalações produtivas e tecnologias para seus produtores.

\section{Referências}

ALMEIDA, Eduardo Simões. Econometria Espacial Aplicada. 1a. ed. Campinas: Alínea Editora, 2012.

ALMEIDA, Eduardo Simões; PEROBELLI, Fernando Salgueiro; FERREIRA, Pedro Guilherme Costa. Existe convergência espacial da produtividade agrícola no Brasil? Revista de Economia e Sociologia Rural, v. 46, p. 31-52, 2008.

ANSELIN, LUC; BERA, Anil. Spatial Dependence in linear Regression Models with an Introduction to Spatial Econometrics. In: ULLAH, A.; GILLES, D.E. (eds.). Handbook of applied economic statistics, Nova York: Marcel Dekker, p. 237-289, 1998.

BRASIL. Blocos políticos e econômicos dos quais o País participa. Disponível em: http://www.brasil.gov.br/governo/2012/07/confira-os-blocos-politicos-e-economicos-dosquais-o-pais-participa. Acesso em: 10 fev. 2021.

CARVALHO, Marcelo Pereira de et al (Ed.). Cenários para o leite no Brasil em 2020. Juiz de Fora: Embrapa Gado de Leite, 2007. 190 p.

CASTRO, Cleber Carvalho de et al. Estudo da Cadeia Láctea do Rio Grande do Sul: uma Abordagem das Relações entre os Elos da Produção, Industrialização e Distribuição. Rev. Adm.

Contemp, Rio de Janeiro, v. 2, n. 1, p.143-164, abr. 1998. Disponível em:

http://www.scielo.br/pdf/rac/v2n1/v2n1a09.pdf. Acesso em: 15 jan. 2021.

CAPUCHO, Thaís Oliveira; PARRÉ, José Luiz. Produção Leiteira No Paraná: Um Estudo Considerando Os Efeitos Espaciais. Informe Gepec, Toledo, v. 16, n. 1, p.112-127, 2012.

Disponível em: http://e-revista.unioeste.br/index.php/gepec/article/view/5103. Acesso em: 10 jan. 2021.

CENTRO DE ESTUdOS AVANÇADOS EM ECONOMIA APLICADA (CEPEA). PIB Agronegócio de Cadeias. Disponível em: https://www.cepea.esalq.usp.br/br/pib-de-cadeiasagropecuarias.aspx. Acesso em: 06 jan.2021.

CONFEDERAÇÃo dA AGRICULTURA E PECUÁRIA DO BRASIL (CNA). Panorama do Agro. Disponível em: https://www.cnabrasil.org.br/cna/panorama-do-agro. Acesso em: 24 mar. 2021 
FERNANDES, Dirney. Diagnóstico do Setor Leiteiro do Rio Grande do Sul no Âmbito do MERCOSUL. Porto Alegre: Emater-rs, 1995. Disponível em:

http://www.emater.tche.br/site/arquivos_pdf/teses/Vol.\%2017\%20-

\%20Diagnostico\%20Setor\%20Leiteiro\%20no\%20RG.pdf. Acesso em: 20 fev. 2021.

FERNANDES, Elizabeth Nogueira; BRESSAN, Matheus; VERNEQUE, Rui da Silva. Zoneamento da pecuária leiteira da região sul do Brasil. Ciência Rural, Santa Maria, v. 34, n. 2, p.485-491, abr. 2004. Disponível em: http://www.scielo.br/pdf/cr/v34n2/a23v34n2.pdf. Acesso em: 20 jan. 2021

FUNDAÇÃO DE ECONOMIA E ESTATÍ́STICA. RS em Mapas e Dados. Disponível em: https://arquivofee.rs.gov.br/rs-em-mapas-e-dados/basedados.html. Acesso em: 14 fev. 2021

INSTITUTO BRASILEIRO DE GEOGRAFIA E ESTATÍsTICA (IBGE). Pesquisa Pecuária

Municipal: Produção de origem animal. Disponível em:

https://sidra.ibge.gov.br/pesquisa/ppm/tabelas. Acesso em: 05 fev. 2021a

INSTITUTO BRASILEIRO DE GEOGRAFIA E ESTATÍ́sTICA (IBGE). Censo Agropecuário 2017.

Disponível em: https://sidra.ibge.gov.br/pesquisa/censo-agropecuario/censo-agropecuario2017. Acesso em: 12 fev. 2021b

JANK, Marcos Sawaya; GALAN, V B. Competitividade do sistema agroindustrial do leite. In: Competitividade no agribusiness brasileiro. São Paulo: Pensa, USP, Julho 1998

LEMOS, Mauro Borges et al. Tecnologia, especialização regional e produtividade: Um estudo da pecuária leiteira em Minas Gerais. Revista de Economia e Sociologia Rural, Brasília, v. 41, n. 3, p.117-138, jan. 2003. Disponível em: http://www.scielo.br/pdf/resr/v41n3/a06v41n3.pdf. Acesso em: 03 fev. 2021.

MAIA, Guilherme Baptista da Silva et al. Produção leiteira no Brasil. BNDS, Rio de Janeiro, v. 37, n. 1, p.371-398, mar. 2013. Disponível em:

https://web.bndes.gov.br/bib/jspui/handle/1408/1514?mode=full. Acesso em: 12 fev. 2021.

MARION FILHO, Pascoal José; OLIVEIRA, Luiz Fernando Valter de. A especialização e a concentração da produção de leite nas microrregiões do Rio Grande do Sul (1990 2007). Ensaios FEE, Porto Alegre, v. 31, n. 1, p.635-647, 2011. Disponível em: <https://revistas.fee.tche.br/index.php/ensaios/article/view/2574>. Acesso em: 10 fev. 2021. MINISTÉRIO DA AGRICULTURA, PECUÁRIA E ABASTECIMENTO (MAPA). Produção de Leite. Disponível em: http://www.agricultura.gov.br/. Acesso em: 26 fev. 2021

PEDROSO, Glaucilene Dias. Setor Leiteiro: as percepções de produtores do RS sobre as transformações delineadas na década de 90. 2001. 120 f. Dissertação (Mestrado) - Curso de Desenvolvimento Rural, Universidade Federal do Rio Grande do Sul, Porto Alegre, 2001. Disponível em: http://www.ufrgs.br/pgdr/teses/downloads. Acesso em: 12 mar. 2021.

PEROBELLI, Fernando Salgueiro; ARAÚJO JUNIOR, Inácio Fernandes de; CASTRO, Lucas Siqueira de. As dimensões espaciais da cadeia produtiva do leite em Minas Gerais. Nova Economia, [s.I.], v. 28, n. 1, p.297-337, abr. 2018. Disponível em: http://www.scielo.br/pdf/neco/v28n1/01036351-neco-28-01-297.pdf. Acesso em: 24 fev. 2021.

PONCIANO, Patricia Ferreira; SCALON, João Domingos. Análise espacial da produção leiteira usando um modelo autoregressivo condicional. Semina: Ciências Agrárias, Londrina, v. 31, n. 2, p.487-496, jun. 2010. Disponível em: http://www.redalyc.org/pdf/4457/445744096022.pdf. Acesso em: 10 mar. 2021. 
RESENDE, João Cesar De et al. Ganho tecnológico na cadeia produtiva do leite. Agroanalysis, v. 31, n. 12, dez. 2016. Disponível em: http://agroanalysis.com.br/12/2016/mercado-

negocios/pecuaria-de-leite-ganho-tecnologico-na-cadeia-produtiva. Acesso em: 08 mar. 2021.

SCHUMACHER, Gabriela. Produção de leite no Rio Grande do Sul: a distribuição espacial e a relação de dependência entre os municípios. 2013. 103 f. Dissertação (Mestrado) - Curso de Administração, Universidade Federal de Santa Maria, Santa Maria, 2013. Disponível em: https://repositorio.ufsm.br/handle/1/4637. Acesso em: 18 fev. 2021.

SILVA, Leonardo Henrique Amaro da; CAMARA, Marcia Regina Gabardo da; TELLES, Tiago Santos. Evolução e distribuição espacial da produção de leite no estado do Paraná, Brasil. Acta Scientiarum: Human and Social Sciences, Maringá,, v. 38, n. 1, p.37-47, jun. 2016. Disponível em: http://periodicos.uem.br/ojs/index.php/ActaSciHumanSocSci/article/view/30006. Acesso em: 08 mar. 2021.

SILVA NETO, Benedito; BASSO, David. A produção de leite como estratégia de desenvolvimento para o Rio Grande do Sul. Desenvolvimento em Questão, ljuí, v. 3, n. 5, p.53-72, jun. 2005. Disponível em:

https://www.revistas.unijui.edu.br/index.php/desenvolvimentoemquestao/article/view/106. Acesso em: 14 mar. 2021.

United States Department of Agriculture (USDA). Production, Supply and Distribuition Dairy. Disponível em: https://apps.fas.usda.gov/psdonline/app/index.html\#/app/downloads. Acesso em: 20 mar. 2021.

VILELA, Duarte et al. (Ed.). Pecuária de leite no Brasil: cenários e avanços tecnológicos. Brasília: Embrapa, 2016. 435 p.

VILELA, Duarte et al. A evolução do leite no Brasil em cinco décadas. Revista de Política Agrícola, Brasília, v. 26, n. 1, p.5-24, jan. 2017. Disponível em: https://seer.sede.embrapa.br/index.php/RPA/article/view/1243. Acesso em: 06 jan. 2021. ZOCCAL, Rosangela et al. A inserção do Brasil no mercado internacional de lácteos. Juiz de Fora: Embrapa Gado de Leite, 2005. 180 p. 